\title{
Operating Characteristics of Diene-Urethane Elastomers on the base of NISSOG 3000 Oligodienediol
}

\author{
VASILIY P. MEDVEDEV ${ }^{1}$, MARAT A. VANIYEV ${ }^{1}$, \\ SAULE A. SAKIBAYEVA² and ANASTASSIYA Y. KOVALEVA ${ }^{2 *}$
}

'Volgograd State Technical University, Russian Federation, 400005, Volgograd, Lenin av., 28.

${ }^{2}$ Auezov South Kazakhstan State University, Kazakhstan, 160012, Shymkent, Tauke Khan av., 5.

*Corresponding author E-mail: anastasiya2301@mail.ru

http://dx.doi.org/10.13005/ojc/320507

(Received: August 26, 2016; Accepted: October 15, 2016)

\begin{abstract}
The article is devoted to the research of the chain branching agent nature impact on the structure and type of vulcanization network crosslinks, the degree of crosslinking and the complex of physico-mechanical properties of polidienuretane on the basis of NISSOG 3000 oligomeric rubber was researched. Interdependence of structural parameters of elastomeric netting and elastic strength properties of the hardened materials was determined. It was defined that a significant contribution to the structure network formation is made by physical bonds due to intermolecular interaction. Using an aromatic diamine allows to increase the share of physical links and ratio of reactive functional groups. The possibility of physical-mechanical indicators of polydieneurethane vulcanization network varying by changing the ratio of reactive functional groups and the type of chain branching agent was proved. The resistance of polyurethane materials on the basis of oligodiendiols in the conditions of thermooxidative aging conditions and it was found that they have a fairly high thermooxidative stability.
\end{abstract}

Keywords: Oligodiendiols, Polyisocyanates, chain branching agent, polydieneurethane, coatings.

\section{INTRODUCTION}

Injection molding compositions on the basis of liquid rubber are becoming more widely used in a production of the manufacture of sealants, waterproofing and sports coatings. Polydieneurethane elastomers on the basis of oligodienedioles are obtained by the method of curing (vulcanizing) due to the reaction between hydroxyl groups of oligomers and isocyanate groups of curing agent in the presence of chain branching agents (CBA).

Curing without the use of CBA is usually leads to elastomers formation with a low degree of crosslinking and insufficient shares elastically active material grid with a rather high content of uncrosslinked phase (sol fraction). Previously, during the studying oligobutadiene rubber curing characteristics with hydroxyl functional groups it was 
found that the use of CBA allows extending molecular chains with hydroxyl end groups, which significantly improves the structural parameters of the grid and increase the elastic-strength properties of obtained polidieneurethanes $^{1,2}$.

Due to the fact that the type of chain branching agent can have a significant impact on the degree of crosslinking, the structural parameters and the complex mechanical properties of elastomers, the actual problem is the reasonable choice of CBA, ensuring the most optimal combination of technological properties of the compositions in their processing and polydieneurethane operating characteristics.

The purpose of this research is to study the effect the type CBA on the structure of vulcanization grid and strength properties of elastomers based on polydieneurethane elastomers on the base of NISSO G 300 oligodienediol, as well as to evaluate the thermo-oxidative stability of obtained polydieneurethanes.

\section{MATERIAL AND METHOD}

As an oligodienediole the NISSO PB rubber stamp $G$ was used. This type of the rubber is characterized by an average molecular weight of 3000 and the number of hydroxyl groups of $1 \%$. The choice of this rubber is determined by the relatively high content of double bonds of the 1,2-addition $(90 \%)$ and a high proportion of bifunctional (above $92 \%$ ) of molecules ${ }^{3}$, as well as the prospect of the practical application of materials based on it because the best properties ${ }^{4}$.

Polydiene urethane elastomers on the base of oligodienediole (brand ПдИ- $1 \mathrm{~K}$ ), which is the copolymer of butadiene with isoprene at the relation of the monomers $0,8: 0,2$ and a hydroxyl content of $1,0 \%$, were objects of comparison. Unlike NISSO PВ, in the molecules of ПДИ- $1 \mathrm{~K}$ units attached to the position of 1,4-cis and 1,4-trans, the combined share of about $80 \%$, are dominated.

Glycerin, triethanolamine (TEA), trimethylphosphate (TMP), aromatic diamine Etakyur 300 (mixture of 2,4- and 2,6-isomers dimethylthiotolyene-diamine) and also hydroxyl containing polyol Laprol 373 were used as agents of chain branching. Laprol 373 is an polyether of propylene oxide with glycerin of molecular weight $370 \pm 20$ (technical requirements of the Russian Federation ${ }^{1}$ 2226-017-10488057-94).

As a curing agent polymethylenephenyl-isocyanate on the base of 4,4'diphenylmethanediisocyanate (technical requirements of the Russian Federation 1 2224152-04691277-96) with content of isocyanate groups $29-32 \%$.

During the research sol-gel method of analysis was applied, that allows depending on the sol fraction content and equilibrium swelling values to determine the structural parameters of elastomers vulcanization grid ${ }^{5,6}$.

Physical and mechanical properties of polydieneurethanes were evaluated in accordance with State Standard 270-75. Thermal oxidative aging was carried out in air at the temperature of $100^{\circ} \mathrm{C}$ for $24,72,168$ and 240 hours, followed by determination of the coefficients change tensile strength and elongation at break.

\section{RESULTS AND DISCUSSION}

As a result of the research it was found out, that the physical and chemical structure of the CBA has a significant influence on physical and mechanical properties of polydieneurethanes. In particular, the data in Figure 1 proves that at the grid branching agent content of $0,12 \mathrm{~mol}$ the strength properties of elastomers with Etakyur 300, Laprol 373 and glycerin significantly higher than materials with TEA and TMP. Thus there is a natural decrease of elongation values by tensile (figure 1 and 2).

Dependences, demonstrated the influence of the functional groups ratio in urethane-formation system on the value of elastic-strength properties of polydieneurethanes, have the analogous characteristics (figures 3 and 4).

Besides the nature of cross-linking bonds, the mechanical properties of elastomers also could be determined by structural features of the grid. In this regard, it was researched the effect of the 
type and amount of CBA on the parameters of the elastomers vulcanization structure (table 1).

As follows from the data in table 1, samples prepared without the use of a CBA, characterized by the lowest values of the crosslinking degree, $\mathrm{Va}$ share, the number of grid chemical cross-points and chemicals, respectively, less value of the equilibrium

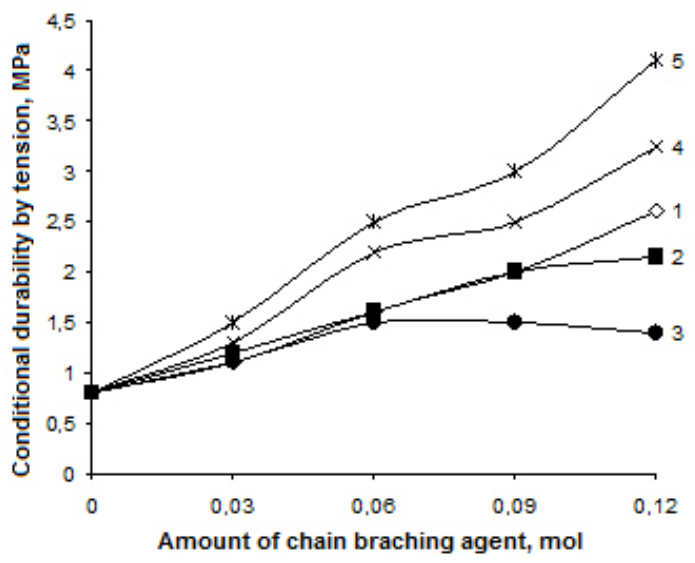

1- glycerin; 2 - TEA; 3 - TMP; 4 - Laprol 373;

5 - Etakyur 300

Fig. 1: Dependence of relative durability by polyurethane tension from amount and type of chain branching agent

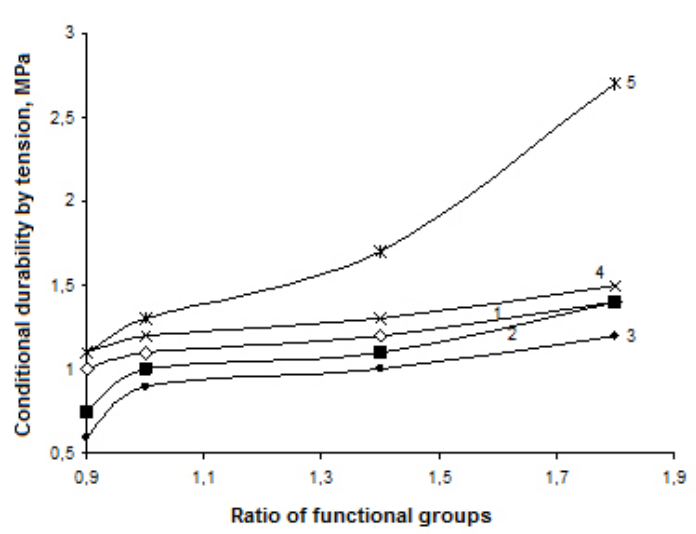

1- glycerin; 2 - TEA; 3 - TMP; 4 - Laprol 373; 5 - Etakyur 300

Fig. 3: Influence of the functional groups ( $\mathrm{NCO}: \mathrm{OH}$ or $\mathrm{NCO}: \mathrm{OH}+\mathrm{NH}_{2}$ ) ratio on an index of conditional durability by tension of polydieneurethanes depending on the type of CBA module. However, polydieneurethanes obtained in the presence of CBA, are significantly different in the parameters of the vulcanization grid. It should be noted that the highest degree of crosslinking is typical for the materials, containing Etakyur 300, glycerin and Laprol 373 as a CBA. Appropriately it influence on such parameters as the proportion of elastically active material of a grid, average

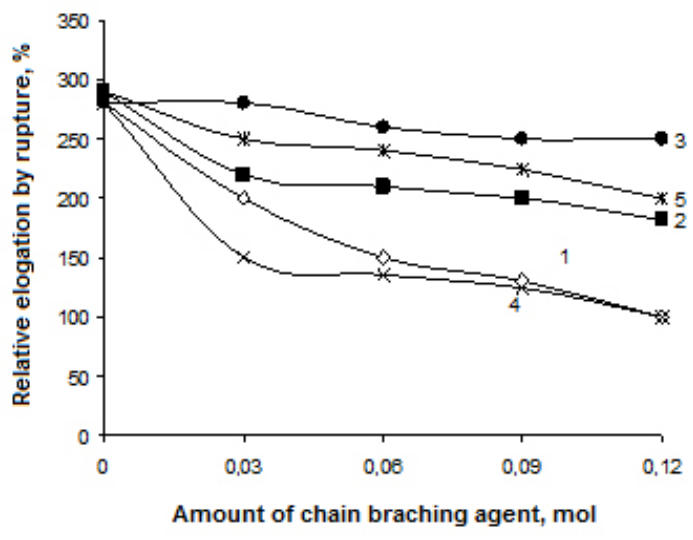

1- glycerin; 2 - TEA; 3 - TMP; 4 - Laprol 373;

5 - Etakyur 300

Fig. 2: Dependence of relative elongation by a rupture of polyurethane from amount and type of chain branching agent

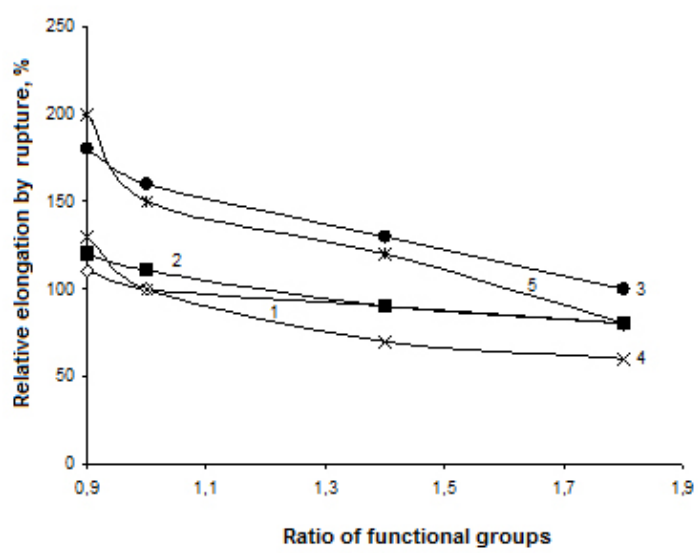

1- glycerin; 2 - TEA; 3 - TMP; 4 - Laprol 373; 5 - Etakyur 300

Fig. 4: Influence of ratio of functional groups ( $\mathrm{NCO}: \mathrm{OH}$ or $\mathrm{NCO}: \mathrm{OH}+\mathrm{NH}_{2}$ ) on the index of relative elongation by rupture of polydieneurethane depending on the type of CBA 
molecular mass of a chain segments $\left(M_{C}\right)$ between the grid and $\mathrm{N}_{\mathrm{c}}$. Simultaneously, from the data of the table 1 shows it can be seen that the difference of values most significantly appears by a dosage of chain branching agent $0,09 \mathrm{~mol}$.

Experimental data presented in table 2 demonstrates the effect of the ratio of functional groups to the number of chemical and physical sites of the grid (as well as their total content) formed by curing in the presence of various types of CBA.

In the case of glycerin using, ensuring the formation of urethane bonds when changing the ratio $\mathrm{NCO}: \mathrm{OH}$ from $0,9: 1$ till 1,8:1 there is a decrease in the values of $M_{C}$ from 3633 to 2012. This leads to a certain increase in strength properties and decrease of elongation values (curves 1 in figures 3 and 4).

In the presence of an aromatic diamine curing may occur not only to form urethane crosslinks, but also the urea-urethane, and an excess of NCO-groups biuret linkages can be formed. In turn, this is reflected in the increasing level of strength properties (curves 5 in figures 1 and 3 ). The important point is that the physical intermolecular bonds, having sufficient lability, provide greater capacity for deformation (5 curves in figures 2 and 4).

Smaller values of durability by tension and crosslinking degree are typical for the cases of triethanolamine and trimethilolphosphate use, are linked, apparently, with the effect of the tertiary nitrogen atom and phosphorus on the reactivity of the hydroxyl groups in these compounds.

An analysis of polydieneurethanes vulcanization grid structural parameters, what was identified by the compressive stress relaxation, shows differences in material properties. Increasing the amount of the polyisocyanate leads to selfassociate of highly polar allophanate, urea-urethane and biurethane groups and microheterogeneous structure formation. In all cases, this leads to a sharp

Table 1: Characteristics* of a vulcanization grid depending on the type and CBA content

\begin{tabular}{|c|c|c|c|c|c|c|c|}
\hline $\begin{array}{l}\text { Chain } \\
\text { branching } \\
\text { agent }\end{array}$ & $\begin{array}{c}\text { Content, } \\
\text { mol }\end{array}$ & $\begin{array}{c}\text { Sol } \\
\text { fraction } \\
\text { amount } \\
\text { S,\% }\end{array}$ & $\begin{array}{c}\text { Degree } \\
\text { of } \\
\text { molecules } \\
\text { sewing } \gamma\end{array}$ & $\begin{array}{l}\text { Share of } \\
\text { elastically } \\
\text { active grid } \\
\text { material, } \mathrm{V}_{\mathrm{a}}\end{array}$ & $\begin{array}{l}\text { Average } \\
\text { molecular } \\
\text { mass of } \\
\text { chain } \\
\text { section } \mathrm{M}_{\mathrm{c}}\end{array}$ & $\begin{array}{c}\text { Number } \\
\text { of chemical } \\
\text { grid cross } \\
\text {-points } \\
\mathrm{Nc} \times 10^{-23} \\
\mathrm{~mol} / \mathrm{m}^{3}\end{array}$ & $\begin{array}{c}\text { Equilibrium } \\
\text { modul Å, } \\
\mathrm{MPa}\end{array}$ \\
\hline & 0 & 14,1 & 1,94 & 0,89 & 4545 & 1,17 & 1,44 \\
\hline \multirow[t]{3}{*}{ Glycerin } & 0,03 & 7,4 & 2,89 & 0,90 & 3045 & 1,74 & 2,15 \\
\hline & 0,06 & 5,97 & 3,25 & 0,91 & 2683 & 1,97 & 2,44 \\
\hline & 0,09 & 1,72 & 6,74 & 0,92 & 1305 & 4,05 & 5,01 \\
\hline \multirow[t]{3}{*}{ Etakyur 300} & 0,03 & 5,21 & 3,61 & 0,90 & 2432 & 2,17 & 2,68 \\
\hline & 0,06 & 3,7 & 4,36 & 0,91 & 2018 & 2,62 & 3,24 \\
\hline & 0,09 & 1,2 & 8,22 & 0,92 & 1069 & 4,95 & 6,11 \\
\hline \multirow[t]{3}{*}{ Laprol 373} & 0,03 & 8,23 & 2,71 & 0,90 & 3248 & 1,63 & 2,01 \\
\hline & 0,06 & 6,04 & 3,21 & 0,90 & 2736 & 1,93 & 2,39 \\
\hline & 0,09 & 3,15 & 4,78 & 0,91 & 1839 & 2,88 & 3,55 \\
\hline \multirow[t]{3}{*}{ TEA } & 0,03 & 7,42 & 2,89 & 0,90 & 3050 & 1,73 & 2,14 \\
\hline & 0,06 & 6,16 & 3,23 & 0,90 & 2726 & 1,94 & 2,40 \\
\hline & 0,09 & 4,26 & 4,02 & 0,90 & 2191 & 2,41 & 2,98 \\
\hline \multirow[t]{3}{*}{ TMP } & 0,03 & 11,6 & 2,19 & 0,89 & 4017 & 1,31 & 1,63 \\
\hline & 0,06 & 9,64 & 2,46 & 0,90 & 3580 & 1,47 & 1,82 \\
\hline & 0,09 & 6,27 & 3,13 & 0,90 & 2755 & 1,92 & 2,37 \\
\hline
\end{tabular}

Annotation: *the results calculated on the data of sol-gel analysis 
increase of the relaxation component of the elastic modulus (figure 5 "a") in comparison with the change in the equilibrium component values (figure 5 «»)). Thus the most significant increase of the relaxation component of module of elasticity $\mathrm{E}_{\text {phys }}$ is typical for elastomers with major polarity of crosslinks obtained using Etakyur 300 (curve 5 in figure 5 "a"). The differences can be seen on the data of dependence $\mathrm{E}_{\text {eq }}$ from functional groups ratio (figure $5 \ll \mathrm{b} »$, curve 5).

As it follows from graphs of figure 6, simultaneously with the growth of physical component of elasticity module, relative share of physical nodes of sewing expressed in terms of the ratio $\mathrm{Nc}_{\text {phys }} / \mathrm{Nc}_{\text {total }}$ (figure 6 "a") increases, with adequate chemical reduction of the share of grid nodes (figure 6 «b») and an increase in the ratio (figure 6 (C) ) between the physical and chemical grid nodes. Overall, these experimental data prove the occurrence of micro heterogeneous structure of polydieneurethanes and the possibility of its control by varying the ratio of $\mathrm{NCO}: \mathrm{OH}$ or $\mathrm{NCO}:\left(\mathrm{OH}+\mathrm{NH}_{2}\right)$.

Polydieneurethanes on the base of researched rubber could be used as sports and roofing coatings, including under conditions of elevated temperature (till $70^{\circ} \mathrm{C}$ ) for open structures. Taking into account that the molecules of NISSO PB G 3000 oligodiendiol contain double bonds in the

Table 2: Characteristics* of a vulcanization grid depending on the CBA type and ratio of functional groups

\begin{tabular}{|c|c|c|c|c|c|}
\hline $\begin{array}{l}\text { Chain branching } \\
\text { agent }{ }^{* *}\end{array}$ & $\begin{array}{l}\text { Functional } \\
\text { groups ratio }\end{array}$ & $\mathrm{M}_{\mathrm{c}}$ & $\begin{array}{c}\mathrm{Nc}_{\text {total }} \times 10^{-23} \\
\mathrm{~mol} / \mathrm{m}^{3}\end{array}$ & $\begin{array}{c}\mathrm{Nc}_{\text {chim }} \times 10^{-23} \\
\mathrm{~mol} / \mathrm{m}^{3}\end{array}$ & $\begin{array}{c}\mathrm{Nc}_{\text {phys }} \times 10^{-23}, \\
\mathrm{~mol} / \mathrm{m}^{3}\end{array}$ \\
\hline \multirow[t]{5}{*}{ Glycerin } & $\mathrm{NCO}: \mathrm{OH}$ & & & & \\
\hline & $0,9: 1$ & 3633 & 1,79 & 1,46 & 0,33 \\
\hline & $1: 1$ & 2907 & 2,32 & 1,82 & 0,50 \\
\hline & $1,4: 1$ & 2575 & 2,80 & 2,06 & 0,75 \\
\hline & $1,8: 1$ & 2012 & 3,71 & 2,63 & 1,08 \\
\hline \multirow[t]{5}{*}{ Etakyur 300} & $\mathrm{NCO}:\left(\mathrm{OH}+\mathrm{NH}_{2}\right)$ & & & & \\
\hline & $0,9: 1$ & 2894 & 2,28 & 1,83 & 0,45 \\
\hline & $1: 1$ & 2123 & 3,18 & 2,49 & 0,69 \\
\hline & $1,4: 1$ & 1885 & 3,86 & 2,81 & 1,04 \\
\hline & $1,8: 1$ & 1848 & 4,19 & 2,87 & 1,32 \\
\hline \multirow[t]{5}{*}{ Laprol 373} & $\mathrm{NCO}: \mathrm{OH}$ & & & & \\
\hline & $0,9: 1$ & 3738 & 1,73 & 1,42 & 0,31 \\
\hline & $1: 1$ & 3115 & 2,09 & 1,70 & 0,39 \\
\hline & $1,4: 1$ & 2692 & 2,56 & 1,97 & 0,59 \\
\hline & $1,8: 1$ & 2031 & 3,60 & 2,61 & 0,99 \\
\hline \multirow[t]{5}{*}{ TEA } & $\mathrm{NCO}:\left(\mathrm{OH}+\mathrm{NH}_{2}\right)$ & & & & \\
\hline & $0,9: 1$ & 3825 & 1,63 & 1,38 & 0,24 \\
\hline & $1: 1$ & 3175 & 2,00 & 1,67 & 0,33 \\
\hline & $1,4: 1$ & 2959 & 2,26 & 1,79 & 0,47 \\
\hline & $1,8: 1$ & 2535 & 2,78 & 2,09 & 0,69 \\
\hline \multirow[t]{5}{*}{ TMP } & $\mathrm{NCO}: \mathrm{OH}$ & & & & \\
\hline & $0,9: 1$ & 4638 & 1,32 & 1,14 & 0,18 \\
\hline & $1: 1$ & 4012 & 1,59 & 1,32 & 0,27 \\
\hline & $1,4: 1$ & 3737 & 1,77 & 1,42 & 0,39 \\
\hline & $1,8: 1$ & 2919 & 2,37 & 1,81 & 0,56 \\
\hline
\end{tabular}

Annotation: *the results calculated on the data of relaxation of tension by compression

${ }^{* *}$ content of CBA is $0,03 \mathrm{~mol}$ 

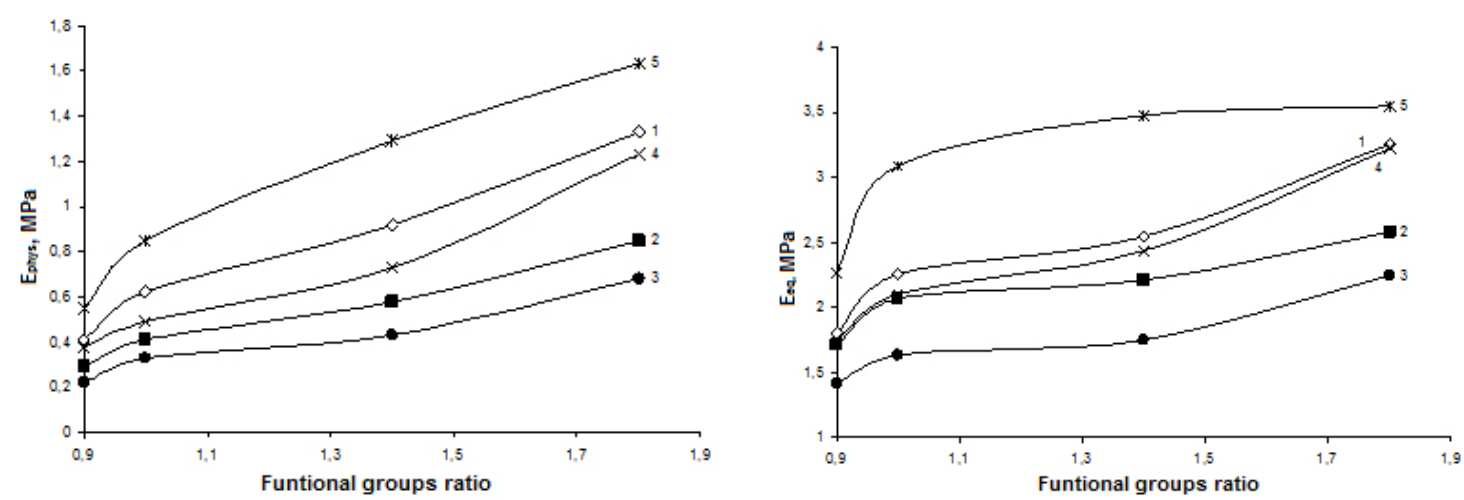

Type CBA: 1- glycerin; 2 - TEA; 3 - TMP; 4 - Laprol 373; 5 - Etakyur 300

Fig. 5: Influence of functional groups ration ( $\mathrm{NCO}: \mathrm{OH}$ or $\mathrm{NCO}: \mathrm{OH}+\mathrm{NH}_{2}$ ) on the elasticity module of physical nodes of a grid (a) and equilibrium module (b)
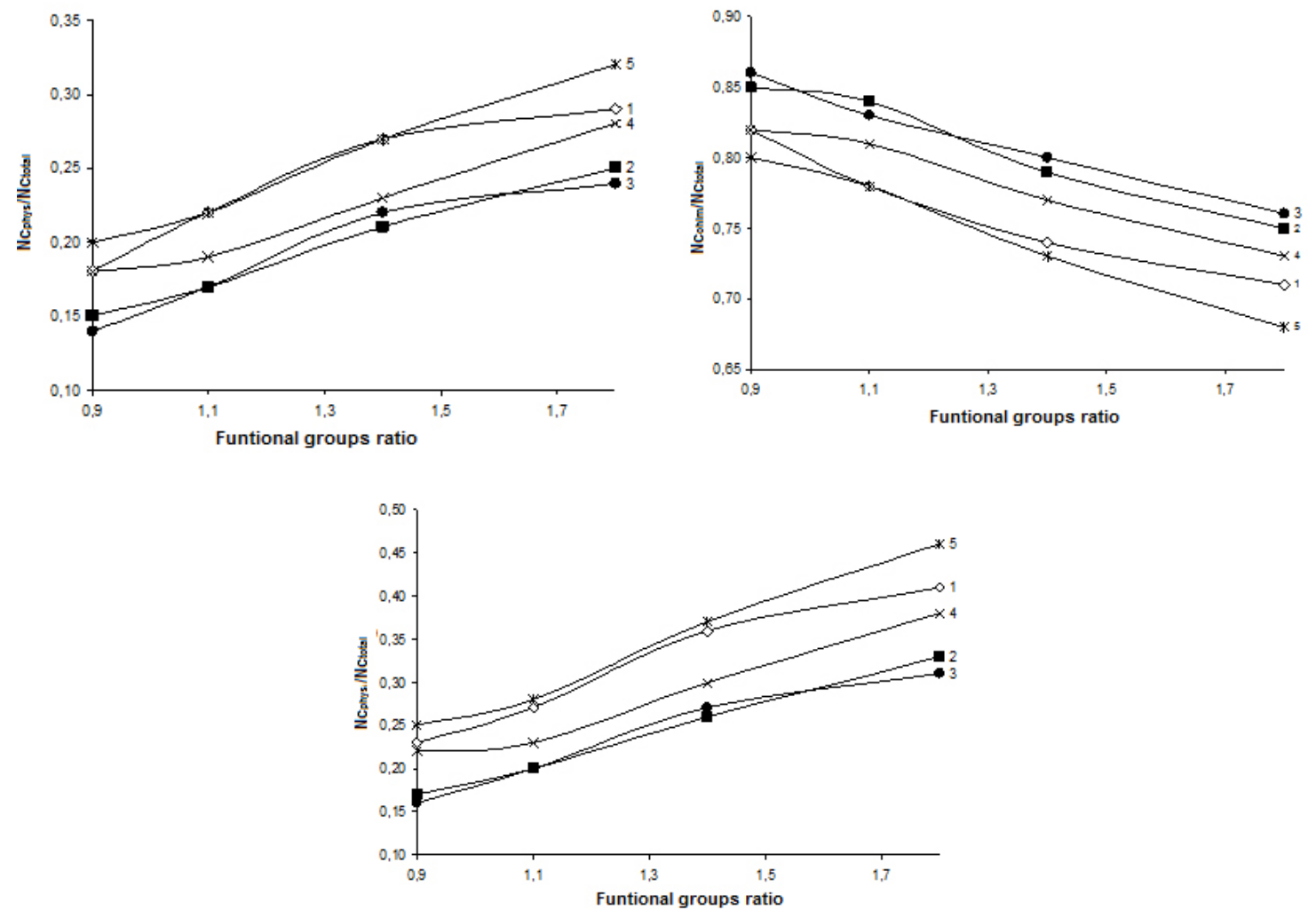

1- glycerin; 2 - TEA; 3 - TMP; 4 - Laprol 373; 5 - Etakyur 300

a - share of grid physical nodes; $b$ - share of grid chemical nodes; $c$ - ratio of the number of physical grid nodes to chemical nodes

Fig. 6: Influence of the functional groups ratio ( $\mathrm{NCO}: \mathrm{OH}$ or $\mathrm{NCO}: \mathrm{OH}+\mathrm{NH}_{2}$ ) on the grid structural parameters of polydieneurethanes depending on the type of CBA 
Table 3: Change coefficient of durability by tension $\left(\kappa_{\sigma}\right)$ and elongation by break $\left(\kappa_{\varepsilon}\right)$ after thermooxidative aging* ${ }^{*}$ of polydieneurethanes depending on the type of CBA, the ratio of functional groups and duration of aging

\begin{tabular}{|c|c|c|c|c|c|c|c|c|c|c|}
\hline \multirow[t]{2}{*}{$\begin{array}{l}\text { Oligodiendiol } \\
\text { type }\end{array}$} & \multirow{2}{*}{$\begin{array}{c}\text { Chain } \\
\text { branching } \\
\text { agent }\end{array}$} & \multirow{2}{*}{$\begin{array}{l}\text { Functional } \\
\text { groups } \\
\text { ratio }\end{array}$} & \multicolumn{4}{|c|}{$\underset{\kappa_{\sigma}}{\text { Aging duration, hours. }}$} & \multicolumn{4}{|c|}{$\underset{\kappa_{\varepsilon}}{\text { Aging duration, hours. }}$} \\
\hline & & & 24 & 72 & 168 & 240 & 24 & 72 & 168 & 240 \\
\hline NISSO PB & Glycerin & $1: 1$ & 1,00 & 1,06 & 1,06 & 1,00 & 0,80 & 0,77 & 0,77 & 0,77 \\
\hline \multirow[t]{4}{*}{ G3000 } & Etakyur 300 & $1: 1$ & 1,08 & 1,08 & 1,04 & 1,04 & 0,93 & 0,93 & 0,93 & 0,93 \\
\hline & Etakyur 300 & $1,8: 1$ & 1,17 & 1,17 & 1,12 & 1,10 & 0,90 & 0,90 & 0,90 & 0,90 \\
\hline & Laprol 373 & $1: 1$ & 1,00 & 0,95 & 0,95 & 0,95 & 0,80 & 0,80 & 0,69 & 0,69 \\
\hline & TEA & $1: 1$ & 1,00 & 0,94 & 0,94 & 0,88 & 0,77 & 0,77 & 0,73 & 0,73 \\
\hline пди-1К & Glycerin & $1: 1$ & 0,75 & 0,50 & 0,25 & 0,10 & 0,62 & 0,50 & 0,25 & 0,13 \\
\hline
\end{tabular}

Annotation: *aging conditions: air quality, temperature $100^{\circ} \mathrm{C}$

chain, from a practical point of view it is important to have the information about thermooxidative stability of materials in conjunction with their structural characteristics, which depend on the type of chain branching agent. The data in table 3 illustrate the effect of a change in the type of CBA to tensile strength and elongation by break of polydieneurethanes after thermooxidative aging.

Analysis of impact CBA nature on physical and mechanical properties changing polydieneurethanes (synthesized in the equivalent moles ratio of the functional groups) after aging indicates a relatively high thermo-oxidative stability of all samples. Several worst results are typical for applications as CBA triethanolamine and Laprol 373, resulting in the loss of the elastic properties and high $\mathrm{K} \varepsilon$ rejection rate from unity.

The highest resistance to oxidative aging fixed in tests with glycerin using and an aromatic diamine Etakyur 300. In the case of polymethylenephenyl-isocyanate excess (ratio of isocyanate groups to sum $\mathrm{OH}+\mathrm{NH}_{2}$ equal to $1,8: 1$, table 3 ) after thermal exposure elastomers strength increases. It could be explained by the formation of additional biuret bonds with a high level of intermolecular interaction.

Data comparison of the samples oxidative stability on the base of oligodienediol with materials based on rubber series ПДИ- $1 \mathrm{~K}$ (comparison sample) indicates a clear advantage of polydieneurethanes, obtained using NISSO PB G 3000 . The higher thermal and oxidative stability of them may be explained by microstructure macromolecules of NISSO PB G 3000 , a feature that is predominantly $(90 \%)$ content of vinyl bonds of 1,2-addition. Thermooxidative effects by used temperature-time conditions are not explicitly accompanied by destruction of circuits and decrease in the degree of crosslinking of the vulcanization grid.

\section{CONCLUSION}

Thus, the research results show the possibility of regulating the physical and mechanical properties of polydieneurethane elastomers based NISSO PB G 3000 oligodienediol by varying the structural parameters of the vulcanization grid by well-founded choice of the CBA type, its amount and content of the polyisocyanate curing agent. Elastomers on the base of researched oligomer have a higher oxidative stability than polydieneurethane, the base of which is an oligomer with primary hydroxyl-containing vinyl units attached at position 1,4-cis and 1,4-trans.

Research carried out in the framework of the state order of the Ministry of Education and Science of the Republic of Kazakhstan under the contract 168 from February 12, 2015. 


\section{REFERENCES}

1. Ukrainskaya S.I., Medvedev V.P., Chapurkin V.V.. Development of receipts and research of the compositions on the base of new hydroxyl containing oligomer rubber // Proceedings of Volgograd State Technical University. Chemistry and technology of elementorganic monomers and polymer materials. . 2012., 7., 154- 159.

2. Medvedev V.P., Ukrainskaya S.I., Chapurkin V.V., Murzin A.V.. Polyurethane elastomers on the base of oligobutandienediol with 1,2structure of double bonds // Caoutchouc è rubber, 2012, 1; 2-5.

3. Special Properties of NISSO-PB [Electronic source] / NIPPON SODA CO., LTD, 2012. Access mode: http://www.nippon-soda.co.jp/ $\mathrm{pb} /$.

4. Medvedev V.P., Ukrainskaya S.I., Chapurkin V.V., Murzin A.V. Polyurethane elastomers on the base of NISSO ĐÂ G3000 oligobutandienediol // Glues. Sealants. Technologies, 2012, 12; 11-15.

5. Sergeyeva L.M., Lipatove Y.S., Binkevich N.I.. Research of the density of spacing grid and nature of cross-linking bonds in polyurethane elastomers // In book. «Synthesis and Physics and Chemistry of polyurethane». - Kiev: Naukova dumka, 1967; 199

6. Beysenbayev O.K., Isa A.B., Kovaleva A.Y. Research of Polyacrylonitrile Saponification Heterophase Process Mechanism in Different Conditions// Orient J Chem2015; 4-9. 